\title{
The Influence of Animacy on Relative Clause Processing
}

\author{
Willem M. Mak \\ Department of Linguistics, University of Nijmegen, the Netherlands \\ Wietske Vonk \\ Max Planck Institute for Psycholinguistics, Nijmegen, The Netherlands, and Department of Linguistics, \\ University of Nijmegen, The Netherlands \\ and \\ Herbert Schriefers \\ Nijmegen Institute for Cognition and Information, University of Nijmegen, the Netherlands

\begin{abstract}
In previous research it has been shown that subject relative clauses are easier to process than object relative clauses. Several theories have been proposed that explain the difference on the basis of different theoretical perspectives. However, previous research tested relative clauses only with animate protagonists. In a corpus study of Dutch and German newspaper texts, we show that animacy is an important determinant of the distribution of subject and object relative clauses. In two experiments in Dutch, in which the animacy of the object of the relative clause is varied, no difference in reading time is obtained between subject and object relative clauses when the object is inanimate. The experiments show that animacy influences the processing difficulty of relative clauses. These results can only be accounted for by current major theories of relative clause processing when additional assumptions are introduced, and at the same time show that the possibility of semantically driven analysis can be considered as a serious alternative. ๑ 2002 Elsevier Science (USA)
\end{abstract}

Key Words: parsing; animacy; relative clauses.

There is a large body of literature on the processing of relative clauses. For many languages, it has been shown that subject relative clauses, such as (1), are easier to comprehend than object relative clauses, such as (2):

(1) Morgen zal de professor, die de studenten ontmoet heeft, de diploma's uitreiken. Tomorrow will the professor, that the students met has, the diplomas present. (Tomorrow the professor, who has met the students, will present the diplomas.)

(2) Morgen zal de professor, die de studenten ontmoet hebben, de diploma's uitreiken. Tomorrow will the professor, that the students met have, the diplomas present.

Address correspondence and reprint requests to W.M. Mak, IWTS, Wundtlaan 1, 6525 XD Nijmegen, The Netherlands. Fax: +31 2435212 13. E-mail: pim.mak@ mpi.nl.
(Tomorrow the professor, whom the students have met, will present the diplomas.)

This has been shown for English (e.g., Ford, 1983; King \& Just, 1991; King \& Kutas, 1995), in which the clause is disambiguated at the word following the relative pronoun, and for French (Frauenfelder, Segui, \& Mehler, 1980; Holmes \& O'Regan, 1981), in which there is no ambiguity because the relative pronoun is marked either as the subject (qui) or as the object (que) of the relative clause. Corresponding results have been obtained for German (Mecklinger, Schriefers, Steinhauer, \& Friederici, 1995; Schriefers, Friederici, \& Kühn, 1995) and for Dutch (Brown, Hagoort, \& Vonk, 2000; Frazier, 1987; Vonk, Brown, \& Hagoort, 2000). Using several different measures, these studies show that object relative clauses are associated with more processing difficulty than subject relative clauses. 
In English, the clause is disambiguated by the word following the relative pronoun (a tensed verb or a NP). Dutch and German relative clauses, however, are verb-final, as shown in (1) and (2). Therefore, in Dutch and German the relative clauses are not disambiguated by the syntactic category of the word following the relative pronoun. In German, in many cases the relative clause is disambiguated by case marking on the relative pronoun or the noun phrase following the relative pronoun. In Dutch, there is no case marking on relative pronouns and full noun phrases, and therefore the relative clauses in (1) and (2) are disambiguated only at the auxiliary. The number-marking on the auxiliary disambiguates the sentence toward a subject relative clause in (1), in which de professor(sg) is the subject of the relative clause, and toward an object relative clause in (2) in which de studen$\operatorname{ten}(\mathrm{pl})$ is the subject of the relative clause.

In Dutch and German it has been investigated whether the assignment of the subject function is influenced by the thematic fit between the entities in the relative clause and the main verb (Brown et al., 2000; Mecklinger et al., 1995; Schriefers et al., 1995; Vonk et al., 2000). In the experiments past participles were used that were biased to take one of the entities in the relative clause as the subject and the other as the object. Sentences like (3) and (4) were presented, in which one of the protagonists, in this case de professor (the professor), is more likely to be the subject of the main verb (opgeleid, educated) than the other (de studenten, the students).

(3) Morgen zal de professor, die de studenten opgeleid heeft, de diploma's uitreiken. Tomorrow will the professor, that the students educated has, the diplomas present.

(Tomorrow the professor, who has educated the students, will present the diplomas.)

(4) Morgen zullen de studenten, die de professor opgeleid heeft, de diploma's ontvangen.

Tomorrow will the students, that the professor educated has, the diplomas receive.
(Tomorrow the students, whom the professor has educated, will receive the diplomas.)

If readers do not commit themselves to an assignment of the subject and object roles before reading the past participle, the thematic fit between the two nouns and the past participle could be used for this assignment. In this case there might be no processing difficulty in object relatives as in (4). If, however, readers commit themselves to an analysis as subject relative clause already before the past participle is read, readers will still show longer reading times in the object relative clauses: They will either have to make a semantically driven reanalysis at the past participle, or a syntactically driven reanalysis at the auxiliary. The results were consistent with the latter prediction: Despite the manipulation of thematic fit, reading times at the auxiliary were still longer in sentence (4) than in sentence (3). This may be taken as evidence for the position that the preference for subject relative clauses arises before the past participle is encountered. When syntactic information (i.e., the number information at the auxiliary) disconfirms the subject relative interpretation, a reanalysis has to be initiated.

However, one may also argue that the manipulation of thematic fit was not strong enough in the experiments described above. The thematic fit between the entities in the relative clause and the main verb may be manipulated more strongly by manipulating the animacy of the entities in the relative clause (cf. Trueswell, Tanenhaus, \& Garnsey, 1994). Trueswell et al. used animacy to manipulate the thematic fit of a sentence-initial NP with the verb that followed it. This manipulation of thematic fit affected the reading times for full and reduced relative clauses. Usually, reduced relative clauses as in (5) lead to longer reading times on the by-phrase than full relative clauses, because readers prefer a main verb reading of the past participle (in (5) examined), which has to be revised on reading the by-phrase. Trueswell et al. showed that the difference between reduced relative clauses and full relative clauses disappeared when the noun before the verb was inanimate, as in (6). 
(5) The defendant examined by the lawyer. . .

(6) The evidence examined by the lawyer . . .

Thus, in this experiment, readers were sensitive to the inappropriateness of the inanimate noun as the subject of the verb and used this information to choose the correct parse of the sentence.

In relative clauses one can also manipulate animacy, in order to influence the choice between a subject and object relative clause. In the object relative clause in (7) readers may use the animacy of the entities in the relative clause to choose the object relative clause reading.

(7) Vanwege het onderzoek moet de computer, die de inbrekers gestolen hebben, nog een tijdje op het politiebureau blijven.

Because of the investigation must the computer, that the burglars stolen have, some time stay at the police station.

(Because of the investigation, the computer, that the burglars have stolen, had to remain at the police station for some time.)

Since animacy information is already available at the antecedent, readers could in principle use this information at an early stage in the processing of relative clauses. At least two prominent theories of sentence processing, the Active Filler Strategy (AFS; Frazier, 1987; Frazier \& Flores d'Arcais, 1989) and the Syntactic Prediction Locality Theory (SPLT; Gibson, 1998), do not predict such influence of animacy. These theories are of special interest here, as they have explicitly addressed the ambiguity between subject and object relative clauses in Dutch.

The AFS is based upon the difference in syntactic structure between subject relative clauses and object relative clauses. According to transformational linguistic theories (see Haegeman, 1994; Radford, 1997), the relative pronoun in the subject relative clause originates in subject position and is then moved to clause-initial position. The relative pronoun in the object relative clause originates in the object position and is also moved to clause-initial position. This is illustrated in sentences (8) and (9), in which $e$ de- notes the original position of the relative pronoun.

(8) This is the man that $e$ has seen the women.

(9) This is the man that the women have seen $e$.

The empty position that the relative pronoun leaves behind in the structure (indicated by $e$ in (8) and (9)) is called a gap, and the relative pronoun is the filler for this gap. The AFS states that when a reader encounters a filler, it is assigned to the earliest possible gap position. In relative clauses, this means that the filler is assigned to the subject position, because that is the earliest position possible. This strategy is correct for subject relative clauses, but is problematic in object relative clauses, because the subject position is occupied (by the noun phrase the women in sentence (8)). Thus, the AFS proposes that the reader chooses the analysis of the relative clause immediately at the relative pronoun. The AFS is based on the syntactic structure of the relative clause. Semantic information cannot influence the parsing decision.

The SPLT (Gibson, 1998) also claims that readers choose the analysis of the relative clause immediately at the relative pronoun. The SPLT posits that readers choose an analysis of the relative clause on the basis of the memory load of the alternatives. According to the SPLT, there is a cost associated with remembering each constituent that is required to complete the current input string as a grammatical sentence. When the reader encounters the relative pronoun, there is a difference in the number of required constituents between subject relative clauses and object relative clauses. To complete the clause as a subject relative clause, two constituents are necessary: a subject NP-trace and a verb. To complete the sentence as an object relative clause, three constituents need to be held in memory: a subject NP, an object NP-trace, and a verb. Because the parser prefers the interpretation with the fewest required constituents, the clause is analyzed as a subject relative clause. The SPLT does not predict that the decision is influenced by the semantic content of the entities in the relative clause.

In the following, we will first present a corpus study of Dutch and German newspaper 
texts, in which we look at the effects of animacy on the distribution of subject and object relative clauses. Next, we will present two processing studies, in which we look at the on-line effect of animacy on the processing of Dutch relative clauses. By manipulating the animacy of the entities in the relative clause one might be able to guide the reader to either interpretation of the relative clause at an early stage. Alternatively, if readers assign the subject and object functions when they read the past participle, the thematic fit of the entities with the past participle may guide the assignment of subject and object functions.

\section{CORPUS STUDY}

In this section we will look at the effect of animacy on the distribution of subject and object relative clauses. Zubin (1979) studied whether there is an effect of animacy on the distribution of relative clauses in which the protagonists differ in animacy. Zubin claims that regularities in language production are driven by saliency and animacy. An entity that is more salient to the speaker will be the subject of the sentence. One of the factors that influences saliency is the givenness of an entity. In relative clauses, the antecedent is given, and the entity within the relative clause is new. Thus, the antecedent is more salient, and will therefore be used as the subject of the relative clause. Also, an animate entity will be preferred over an inanimate entity as the subject of the sentence. As a result, there are two forces at work in the production of relative clauses in which the protagonists differ in animacy: The first is the tendency to use the antecedent noun as subject of the relative clause, and the second is the tendency to use an animate entity as the subject of the relative clause.

Zubin (1979) found evidence for this account in a corpus study of German relative clauses with an animate and an inanimate entity. He divided the relative clauses of the corpus into four categories, illustrated in (10) to (13). In (10) and (11) the antecedent is animate, and the entity in the relative clause is inanimate. Sentence (10) is a subject relative clause and sentence (11) is an object relative clause. In sentences, (12) and
(13) the antecedent is inanimate, and the entity in the relative clause is animate. Sentence (12) is a subject relative clause; sentence (13) is an object relative clause. The number of relative clauses in each category in his corpus is given in parentheses.

(10) . . . der Junge, der den Stein warf. (103) ... the boy, that(nom) the stone (acc) threw.

(. . . the boy that threw the stone)

(11) . . . der Junge, den der Stein traf.

... the boy, that(acc) the stone (nom) hit.

(. . . the boy that the stone hit)

(12) . . . der Stein, der den Jungen traf. (125) ... the stone, that(nom) the boy (acc) hit.

(. . . the stone that hit the boy)

(13) . . . der Stein, den der Junge warf. (181)

... the stone, that (acc) the boy (nom) threw.

(. . . the stone that the boy threw)

In (10) and (11) the tendency to use the antecedent of the relative clause as subject and the tendency to use an animate entity as subject work together to favor Junge as the subject of the relative clause. In sentences like these, subject relative clauses, as in (10), frequently occur, whereas object relative clauses, as in (11), are infrequent. In (12) and (13), Stein is available as the subject of the relative clause because it is the antecedent, and Junge( $n$ ) is available as the subject of the relative clause because it is animate. In these categories, both subject relative clauses, as in (12) and object relative clauses, as in (13), occur rather frequently.

In most experiments that found a preference for subject relative clauses, both entities were animate. This category, as well as the category with two inanimate entities, was not included in Zubin's study. In our corpus study on Dutch and German newspaper texts, these categories were included. For the Dutch corpus study we used two editions of the daily newspaper Trouw (September 16 and 17, 1993). These texts contained 120,000 words. For the German corpus study, we used four editions of the Internet version of the daily newspaper Die Welt (November 15, 19, 
and 20, 1995, and December 2, 1995). These texts contained 75,000 words.

Because we wanted our analysis to resemble the sentences used in on-line studies we selected from the corpus only relative clauses with transitive verbs. Relative clauses with intransitive verbs do not have an object (as in the man who walks there), and are therefore by definition subject relative clauses. Also, we only included in the analysis the cases in which both the antecedent and the entity introduced in the relative clause were full NPs. Relative clauses with pronouns were not included, since pronouns affect the distribution of subject and object relative clauses in the corpus (Fox \& Thompson, 1990). Though this is an interesting issue in its own right, it goes beyond the focus of the present article.

In the Dutch corpus there were 794 relative clauses. There were 428 relative clauses with intransitive verbs, and 80 with a prominal NP. The remaining 286 relative clauses contained both a subject and an object, with a full NP as antecedent, and a full NP inside the relative clause. Table 1 shows the distribution of subject relative clauses and object relative clauses as a function of the animacy of the antecedent NP and the animacy of the full noun phrase in the relative clause. $^{1}$

The results in Table 1 show that the object relative clauses almost exclusively occur in the condition in which the antecedent NP is inanimate and the NP in the relative clause is ani-

\footnotetext{
${ }^{1} \mathrm{~A}$ noun was coded as animate when it denoted humans (proper names or roles), groups of humans (e.g., the meeting in the meeting decided. . .), or animals.
}

mate. It is important to note that there were no object relative clauses in the condition with an animate antecedent NP and an animate NP inside the relative clause, which is the type of relative clause that has been used in the experiments contrasting subject and object relative clauses in Dutch and German.

Table 2 shows the corresponding results of the German corpus. Again, the analysis was restricted to sentences in which both the antecedent NP and the NP in the relative clause were full NPs. The comparison of Dutch and German is interesting, because of the difference between Dutch and German with respect to case marking. Unlike Dutch, German relative clauses are often disambiguated by case marking on the relative pronoun or the full NP in the relative clause. This was the case in $45 \%$ of the relative clauses in our corpus. In Table 2, the results for the relative clauses that were not disambiguated by case marking are given in parentheses.

Table 2 shows that the German data are similar to the Dutch data. In German too, object relative clauses are almost exclusively found in the condition with an inanimate antecedent NP and an animate NP in the relative clause. As in the Dutch corpus, object relative clauses with an animate antecedent NP and an animate NP in the relative clause are very infrequent. Interestingly, the relative clauses that are disambiguated by case marking show the same distribution as the overall data.

The Dutch and German corpus data thus replicate and also extend the results from Zubin (1979). In the sentences in which the NPs do not differ in animacy, there are more subject relative clauses than object relative clauses. This is com-

TABLE 1

Number of Subject and Object Relative Clauses in the Dutch Corpus as a Function of the Animacy of the Antecedent NP and the Animacy of the NP in the Relative Clause

\begin{tabular}{lcccccr}
\hline & \multicolumn{2}{c}{ Animate antecedent } & & \multicolumn{2}{c}{ Inanimate antecedent } & \\
\cline { 2 - 3 } & $\begin{array}{c}\text { Animate NP } \\
\text { in relative clause }\end{array}$ & $\begin{array}{c}\text { Inanimate NP } \\
\text { in relative clause }\end{array}$ & & $\begin{array}{c}\text { Animate NP } \\
\text { in relative clause }\end{array}$ & $\begin{array}{c}\text { Inanimate NP } \\
\text { in relative clause }\end{array}$ & Total \\
\hline Subject relative clauses & 21 & 119 & & 13 & 53 & 206 \\
Object relative clauses & 0 & 2 & & 70 & 8 & 80 \\
Total & 21 & 121 & & 83 & 61 & 80 \\
\hline
\end{tabular}


TABLE 2

Number of Subject and Object Relative Clauses in the German Corpus as a Function of the Animacy of the Antecedent NP and the Animacy of the NP in the Relative Clause

\begin{tabular}{lcccccrr}
\hline & \multicolumn{2}{c}{ Animate antecedent } & & \multicolumn{2}{c}{ Inanimate antecedent } & \\
\cline { 2 - 3 } & $\begin{array}{c}\text { Animate NP } \\
\text { in relative clause }\end{array}$ & $\begin{array}{c}\text { Inanimate NP } \\
\text { in relative clause }\end{array}$ & & $\begin{array}{c}\text { Animate NP } \\
\text { in relative clause }\end{array}$ & $\begin{array}{c}\text { Inanimate NP } \\
\text { in relative clause }\end{array}$ & Total \\
\hline Subject relative clauses & $18(5)$ & $64(29)$ & & $15(7)$ & $47(34)$ & 144 \\
Object relative clauses & $1(1)$ & 1 & $(1)$ & & $21(13)$ & 1 & $(1)$ \\
Total & 19 & 65 & & 36 & 48 & 24 \\
\hline
\end{tabular}

Note. The results for the relative clauses that are not disambiguated by case marking are given in Parentheses.

patible with Zubin's ideas, because when the entities do not differ in animacy, the tendency for the antecedent to be subject of the relative clause causes a predominance of subject relative clauses.

The corpus studies show that animacy influences the distribution of relative clauses. Also, the corpus studies show that the object relative clauses that have been used in most previous comprehension studies are very infrequent. The question thus arises, whether in comprehension a subject preference will also be visible when the object of the relative clause is inanimate. In this type of relative clause both subject relative clauses (with an animate antecedent and an inaminate NP in the relative clause) and object relative clauses (with an inanimate antecedent and an animate NP in the relative clause) have a high frequency in the corpus.

Evidence that animacy information affects processing immediately comes from a study by Weckerly and Kutas (1999). In an ERP study using object relative clauses with either an animate or an inanimate antecedent Weckerly and Kutas showed that animacy effects are visible already at the antecedent itself. ERPs to inanimate antecedent nouns were more negative than ERPs to animate antecedent nouns. Since animacy affects processing this early, readers should in principle be able to use the animacy cue to guide the assignment of subject and object roles in the relative clause. Whether readers actually do so, was tested in two experiments. Experiment 1 was a self-paced reading study, using the moving window technique, in which we established the basic effects. Experiment 2 was an eye-movement experiment. Eye-movement research has been shown to provide a very direct measure of the cognitive comprehension processes (e.g., Henderson \& Ferreira, 1990). Therefore we used this method to assess the time-course of the effects.

\section{EXPERIMENT 1}

In the experiments, participants read subject and object relative clauses, similar to the ones used in Schriefers et al. (1995), Brown et al. (2000), and Vonk et al. (2000). In these relative clauses the animacy of the object of the relative clause was varied. The four conditions are illustrated in Table 3. In (A) and (B), both the antecedent NP and the NP in the relative clause were animate, the type of relative clauses used in previous experiments in Dutch and German. In the subject relative clauses with an inanimate object (C), the antecedent NP was animate and the NP in the relative clause was inanimate. Finally, in the object relative clauses with an inanimate object (D), the antecedent NP was inanimate and the NP in the relative clause was animate.

If readers do not use the animacy of the NPs in the assignment of the syntactic function of subject and object to the NPs, reading times at the syntactically disambiguating auxiliary in (B) and (D) should be increased, compared to (A) and (C), respectively. However, if readers do use the animacy cue in (C) and (D) in the assignment of syntactic functions, the difference between (C) and (D) may either show up earlier, if a reanalysis is initiated on the basis of the animacy cue, or even be absent if the animacy cue guides the initial parsing decision. 


\section{TABLE 3}

Example Materials in Experiment 1

(A) Subject Relative Clause, Animate Object

Vanwege het onderzoek moeten de inbrekers, die de bewoner beroofd hebben, nog een tijdje op het politiebureau blijven. Because of the investigation must the burglars, who the occupant robbed have, some time stay at the police station. "Because of the investigation, the burglars, who robbed the occupant, had to stay at the police station for some time."

(B) Object Relative Clause, Animate Object

Vanwege het onderzoek moet de bewoner, die de inbrekers beroofd hebben, nog een tijdje op het politiebureau blijven. Because of the investigation must the occupant, who the burglars robbed have, some time stay at the police station. "Because of the investigation, the occupant, who the burglars robbed, had to stay at the police station for some time."

(C) Subject Relative Clause, Inanimate Object

Vanwege het onderzoek moeten de inbrekers, die de computer gestolen hebben, nog een tijdje op het politiebureau blijven. Because of the investigation must the burglars, who the computer stolen have, some time stay at the police station.

"Because of the investigation, the burglars, who stole the computer, had to stay at the police station for some time."

(D) Object Relative Clause, Inanimate Object

Vanwege het onderzoek moet de computer, die de inbrekers gestolen hebben, nog een tijdje op het politiebureau blijven. Because of the investigation must the computer, that the burglars stolen have, some time stay at the police station.

"Because of the investigation, the computer, that the burglars stole, had to remain at the police station for some time."

\section{Method}

Participants. Forty students of the University of Nijmegen participated in the experiment. They were native speakers of Dutch. They were paid for their participation.

Materials and design. We constructed 32 sets of four sentences. An example of a set of four sentences is given in Table $3 .^{2}$ The first sentence of each set (sentence A in Table 3) contained a subject relative clause with an animate subject and an animate object. The second sentence (B) was the object relative clause counterpart of this sentence: These were derived by exchanging the antecedent NP and the NP in the relative clause. The third sentence (C) contained a subject relative clause, with an animate subject, but an inanimate object. The fourth sentence (D) was the object relative clause counterpart of the third sentence. The relative clauses consisted of the sequence die de 〈noun〉 〈past participle〉 heeft/hebben (see Table 3). After heeft/hebben there was a comma, and after the comma there were at least three other words that completed the main clause. Note that the relative pronouns in our items were the same in all conditions. We did not use neuter nouns, because the neuter rel-

\footnotetext{
${ }^{2}$ The relative clauses in the experiment are generally read as nonrestrictive, but need not in proper context.
}

ative pronoun dat also functions as the complementizer in Dutch.

In sentences with an animate and an inanimate protagonist, it is not possible to select verbs that are semantically unbiased with respect to which protagonist is most likely to be the subject of the relative clause. Therefore, in the sentences with two animate protagonists, we also selected verbs for which one of the nouns was most likely to be the subject and the other most likely to be the object. The biases were established in a pretest, in which participants were shown the nouns paired with the verb, as in (14):

(14) De inbrekers beroven de bewoner The burglars rob the occupant

\section{5}

De bewoner berooft de inbrekers. The occupant robs the burglars

In half of the items the sentence that was expected to be judged as most likely was presented on the left, in the other half it was presented on the right. In one half of the cases the protagonist that was expected to be judged as the most likely subject was singular, in the other half it was plural. Twenty participants rated on a 5-point scale, which of the two situations described was more likely. The scores were recoded into a 5-point scale in which the lower end of the scale represented the sentence that was expected to be judged as most likely and the upper end the sen- 
tence that was expected to be judged as not likely. Thus, if readers chose the end of the scale closest to the biased item, the score would be 1 . The thirty-two items used in the experiment had a mean score of less than 1.5 and a standard deviation smaller than 1 . The triplets of the two nouns and the verb in the inanimate object condition were not tested for semantic bias, because only one interpretation is possible. The two sets of past participles were matched for length: Both sets had a mean length of 9.25 letters $(F<$ $1)$. They were not matched for frequency: The $\log$ frequencies of the past participles in the animate object condition and the inanimate object condition in the CELEX Dutch database (1998) were 2.06 and 2.73 , respectively $(F(1,31)=$ 14.03, $p=.001)$. There were three sets of nouns: The subjects of the relative clause (de inbrekers in the example), the animate objects (de bewoner), and the inanimate objects. The three sets of nouns were matched for length: The length of the three sets was 8.78, 8.53, and 8.50, respectively $(F<1)$. They were also matched for frequency: The log frequencies were 2.70, 2.65 , and 2.44, respectively $(F<1)$.

An example of the layout of the sentences on the screen is shown in (15) (see Table 3 (A) for the English translation).

\section{(15)}

Vanwege het onderzoek moeten de in brekers, die de bewoner beroofd hebben, nog een tijdje op het politiebureau blijven.

The first line contained the main clause up to the antecedent NP, the second line contained the relative clause and at least two words of the continuation of the main clause, and the third line contained the remaining part of the sentence.

The 32 experimental sentences were mixed with 40 filler sentences. Twenty-eight of these had constructions that were unrelated to the relative clauses. The remaining 12 fillers contained relative clauses, with an inanimate subject and an animate object. An example of such a filler sentence is given in (16).

(16) De organisatie heeft de tentoonstelling, die duizenden bezoekers getrokken heeft, met een maand verlengd.
The organizers have the exhibition, that thousands of visitors attracted has, for a month prolonged.

(The organizers prolonged the exhibition, that attracted thousands of people, for a month.)

Six of these filler sentences were subject relative clauses and six were object relative clauses. These fillers were included to prevent the situation that an inanimate noun would always function as the object of the relative clause. Thus, participants could not develop an experimentspecific strategy.

To make sure that the participants read the sentences carefully, verification statements were included after $25 \%$ of experimental and filler trials. Care was taken that the statements did not draw the attention of the participant to the experimental manipulation. An example is the statement Er wordt een onderzoek verricht (An investigation is being held) for the sentences in Table 3.

The 32 experimental sentences and 40 fillers were pseudo randomly divided into two blocks of trials. Four experimental versions were constructed. The items occurred in the same order in each version. The experimental versions were constructed such that each item occurred in every condition. The participants saw each item only once and saw eight experimental items in each condition. Each block was preceded by six practice trials. Before starting the first experimental block the participants were presented with a practice block consisting of 14 trials. The practice items had constructions similar to the ones used in the experiment.

Procedure. Participants were tested individually. They were seated in a dimly lit room in front of a PC monitor and a panel with three buttons. The course of a trial was as follows. The participants saw a fixation point, indicating where the sentence would begin. By pushing the middle button they started the trial. The participants then saw the whole sentence, but the letters and commas were replaced by dashes. Only the full stop at the end of the sentence was visible. When the participants pressed the middle button again, the first word of the sentence ap- 
peared. They pushed the middle button again when they had read the word. At this button press the first word was replaced by dashes, and the second word appeared. This was repeated until the participants had read the whole sentence. When there was a comma following a word, it was presented together with that word. In most of the trials, when the participants pressed the middle button after the last word of the sentence, they saw the fixation point indicating the next trial, but in some cases the participants saw the word bewering (statement) for $1 \mathrm{~s}$. The participants then saw a verification statement about the sentence. The participants had to judge whether this statement was consistent with the content of the sentence they had just read. If it was consistent they had to press the right button, if not they had to press the left button.

\section{Results}

Reading times longer than $4000 \mathrm{~ms}$ (8 cases, $0.03 \%$ ) were excluded from further analysis. From the remaining reading times those that were more than two standard deviations away from the participant and item means at a given position in each condition (254 cases, 1.25\%), were excluded. On average, the participants gave the correct answer to $95 \%$ of the comprehension questions.
Table 4 presents the mean reading times as a function of the type of relative clause and the animacy of the object for all word positions from the verb of the main clause up to and including two words after the auxiliary, and for the last word of the sentence. For each position presented in Table 4, two analyses of variance were computed, one with participants (F1) and one with items (F2) as a random variable. Animacy of Object (animate object vs inanimate object) and Clause Type (subject relative clause vs object relative clause) were the factors in the analyses.

There were no main effects or interactions at the verb in the main clause. At noun 1 there was an effect of Clause Type $(F l(1,39)=8.26, p<$ $.01 ; F 2(1,31)=8.03, p<.01)$ : At this position subject relative clauses were read faster than object relative clauses. This effect was unexpected, but may be due to the fact that at this position two different sets of nouns were compared. However, at the noun in the relative clause, the same two different sets of nouns were compared. At that position, there was no difference $(F 1<1 ; F 2(1,31)=1.07, p=.31)$.

The sentences were syntactically disambiguated at the auxiliary. The only significant result at this position was an effect of Animacy of Object: the sentences with an animate object

\section{TABLE 4}

Mean Reading Times in Experiment 1 as a Function of Animacy of Object and Clause Type

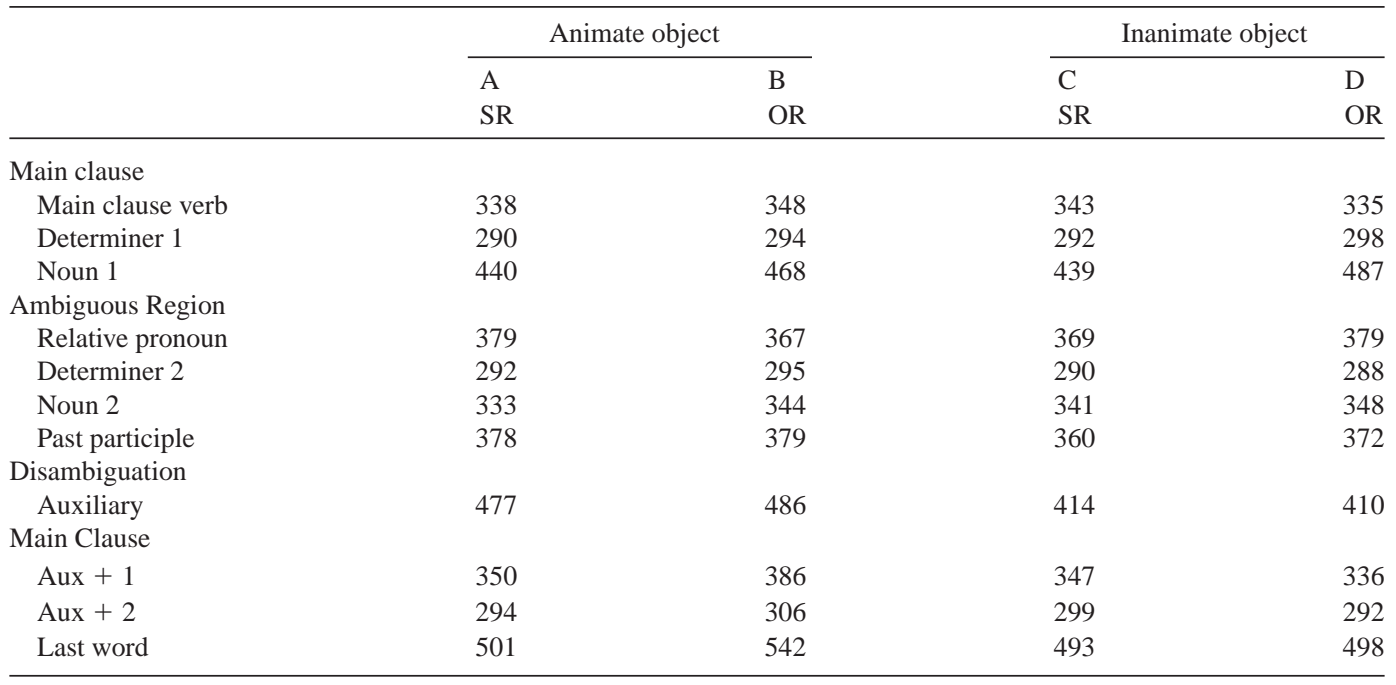


were read significantly slower than the sentences with an inanimate object $(F 1(1,39)=$ $12.12, p=.001 ; F 2(1,31)=10.31, p<.005)$. There was no effect of Clause Type at this position (both Fs $<1$ ). Also, there was no interaction of Clause Type and Animacy of Object (both Fs $<1$ ).

At the first word after the auxiliary, however, there was a main effect of Clause Type in the participant analysis $(F 1(1,39)=4.11, p<.05)$, but in the item analysis this effect was not significant $(F 2(1,31)=2.17, p>.15)$. There was also a main effect of Animacy of Object $(F 1(1,39)=14.24, p=.001 ; F 2(1,31)=8.48$, $p<.01)$. These main effects were qualified by an interaction of Animacy of Object and Clause Type at this position: $F 1(1,39)=16.33, p<$ $.001 ; F 2(1,31)=11.67, p<.005$. Separate analysis at this position for the animate object and the inanimate object condition showed that the effect of Clause Type was significant in the animate object condition $(F 1(1,39)=12.56$, $p<.001 ; F 2(1,31)=11.42, p<.005)$, but not in the inanimate object condition $(F 1(1,39)=$ $2.58, p>.10 ; F 2(1,31)<1)$.

At the last word of the sentence the pattern of reading times was similar to the pattern of reading times at the first word after the auxiliary. At this position, however, the only significant result was the main effect of Animacy of Object in the analysis over participants: $F 1(1,39)=4.24$, $p<.05$. In the items analysis this effect was not significant: $F 2(1,31)=1.24, p=.27$. The interaction of Animacy of Object and Clause Type was not significant either: $F 1(1,39)=1.37 ; p>$ $.20 ; F 2<1$. At the other positions, there were no main effects or interactions.

\section{Discussion}

An effect of Animacy of Object was found at the auxiliary. At this position, the sentences with two animate NPs had longer reading times than the sentences with an animate and an inanimate NP. One must be careful interpreting this main effect, because different past participles were used in the animate object and the inanimate object conditions, and there was a frequency difference between the two sets of past participles. Also, the effect may be due a plausibility differ- ence between the relative clauses with an animate object and the relative clauses with an inanimate object. However, the effect may mean that it was more difficult for the readers to decide on subject and object functions in the animate object condition, that is, the condition with two animate protagonists, than in the inanimate object condition, in which there was one animate and one inanimate protagonist. The crucial question, however, is whether there was an interaction between Animacy of Object and Clause Type. At the word following the auxiliary, this was indeed the case. In the inanimate object condition there was no difference in reading times between the subject relative clause and the object relative clause immediately after the auxiliary, whereas in the animate object condition, the reading times at this position were longer for the object relative clause than for the subject relative clause. In fact, the reading time at the first word after the auxiliary for the object relative clauses with an inanimate object was equal to the reading times for subject relative clauses with an animate object. Apparently, the participants only had difficulty reading object relative clauses when both the subject and the object were animate.

The difference in reading time between the subject relative clauses and the object relative clauses with an animate object did not occur at the disambiguating auxiliary, but at the word after it. This may be a consequence of the fact that readers started a reanalysis some time after the disambiguation, but it may also be a consequence of the fact that in self-paced reading there are often spill-over effects to the next word (Just, Carpenter, \& Woolley, 1982). This may explain the absence of an interaction at the auxiliary. If the effect originating at the auxiliary shows up at the following word, the main effect of Animacy of Object that was found at the auxiliary may also originate from the previous word, i.e., the past participle. The crucial finding in the experiment is that in the inanimate object condition there was no sign of a difference between the subject relative clauses and the object relative clauses at the disambiguating auxiliary or later in the sentence. Also, there were no differences in reading times at earlier positions 
in the relative clause. In the animate object condition object relative clauses lead to longer reading times at the word following the auxiliary.

The only difference in reading time between the sentences with inanimate objects appeared at the noun before the relative clause. This effect may be due to the fact that the words used in that position are different across conditions. If that explanation holds, however, there should also have been a difference at the noun in the relative clause, because the same sets of nouns are compared there. We will return to this issue in the discussion of Experiment 2.

\section{EXPERIMENT 2}

The self-paced reading experiment shows that there is no difference in reading time between subject and object relative clauses when the object of the relative clause is inanimate. In Experiment 2 we wanted to gain more insight into the nature of the effects: Is the interaction between Clause Type and Animacy of Object, which was observed at the word after the disambiguating auxiliary in Experiment 1, an effect that originates from the auxiliary, or from wrap-up processes at the end of the relative clause? We therefore conducted an eye-tracking experiment with the same kind of materials as in Experiment 1. A prepositional phrase was added after the auxiliary in the relative clause to separate effects originating from the auxiliary from end-ofclause wrap-up effects. If the processing problems are immediate syntactic problems, there should be differences in the initial reading of the auxiliary. If the processing differences only show up in the wrap-up processes at the end of the clause, there should only be differences at the final noun of the relative clause, before the comma.

We used two dependent measures. As a measure of immediate processing, we used the firstpass reading times (e.g., Rayner, 1998). To measure wrap-up processes at the end of the relative clause, we used the regression path duration (Konieczny, 1996; Konieczny, Hemforth, Scheepers, \& Strube, 1997), which includes both first-pass reading times and the duration of the regression path. If the effects are due to wrap-up processes at the end of the clause, this may be visible in first-pass reading times, but it may also be visible in longer regression paths originating from the clause-final word. ${ }^{3}$

\section{Method}

Participants. Thirty-two students of the University of Nijmegen participated in the experiment. They were native speakers of Dutch. All had normal or corrected to normal vision. The participants were paid for their participation.

Materials. Forty-eight sets of four sentences were used in the experiment. We added 16 new sets of sentences to the 32 sets that were used in Experiment 1. A prepositional phrase was added after the auxiliary in the relative clause. ${ }^{4}$ This is illustrated in (17) for version (A) of Table 3.

(17) Vanwege het onderzoek moeten de inbrekers, die de bewoner beroofd hebben in het weekend, nog een tijdje op het bureau blijven.

Because of the investigation must the burglars, who the occupant robbed have over the weekend, some time stay at the police station.

(Because of the investigation, the burglars, who robbed the occupant over the weekend, had to stay at the police station for some time.)

The conditions were the same as in Experiment 1. As in Experiment 1, the past participles in the animate object condition and the past participles in the inanimate object condition were matched for length (the mean length was 9.27 in both conditions; $F<1$ ), but not for frequency $(F(1,47)=13.27, p=.001)$. The log frequencies were 2.07 and 2.70 for the past participles in the animate and the inanimate condition, respectively. There were three sets of nouns: The subjects in the relative clause (inbrekers in the example), the animate objects (bewoner), and the inanimate objects (computer). These were

\footnotetext{
${ }^{3} \mathrm{We}$ did not use percentages of regressions to measure wrap-up processes, because we expected these to be similar in all cases where wrap-up processes occur (cf. Rayner, Kambe, \& Duffy, 2000).

${ }^{4}$ Though adding a prepositional phrase after the clause final verb cluster is not possible in other verb-final languages, such as German, it is perfectly natural in Dutch.
} 
matched for length $(F<1)$ : The mean length was $8.15,8.29$, and 8.31 for the subjects, the animate objects, and the inanimate objects, respectively. The nouns were also matched for frequency $(F(1,46)=1.34, p=.27)$. The $\log$ frequencies were $2.77,2.72$, and 2.62 for the subjects, the animate objects, and the inanimate objects, respectively.

The 48 experimental sentences were mixed with 60 filler items. Forty-two of the filler items did not contain relative clauses. The remaining 18 fillers contained relative clauses with inanimate subjects and animate objects. Nine of those were subject relative clauses, and the other nine were object relative clauses. As in Experiment 1 , these fillers were included to avoid a situation in which the inanimate nouns always were the object of the relative clause. Thus, participants could not develop an experiment-specific strategy. The layout of the sentences on the screen was the same as in Experiment 1: On the second line, there were at least two words after the relative clause.

The 108 sentences were pseudorandomly divided into two blocks of trials, each of which was preceded by six practice items. Four experimental versions were constructed. The items occurred in the same order in each version. The experimental versions were constructed such that each item occurred in every condition. The participants saw each item only once, and saw 12 experimental items in each condition. Before the first experimental block the participants were presented with a practice block consisting of 14 items.

Apparatus. The materials were presented on a NEC MultiSync 5FG computer monitor in 800 $\times 600$ pixel mode. The distance between the participants' eyes and the monitor was 85 centimeters, making $1^{\circ}$ of visual angle equivalent to 4.4 character positions.

The eye movements were recorded using an AmTech ET3 eye tracker. Both X and Y positions were collected with a sample frequency of $200 \mathrm{~Hz}$, and a spatial resolution of $.25^{\circ}$. Only the movements of the right eye were recorded, although vision was binocular. Head movements were restricted by the use of a chin and forehead rest and a bite bar.
Procedure. Before the experiment each participant was told about the purpose of the apparatus. Two tests were done to assess the quality of the participants' vision. Then the apparatus was adjusted, so that the participant would be seated as comfortable as possible, and the bite bar was prepared. The calibration procedure for the eye tracker was explained and the participants were instructed to read the sentences so that they understood the meaning and would be able to verify statements about them.

Each block started with a calibration, and there was an additional calibration in the middle of each experimental block. Each experimental block contained 60 sentences. Before every four sentences a short recalibration was performed to correct for possible shifts in head position after the calibration. Each trial started with an asterisk indicating where the next sentence would start. The participants were instructed to look at the asterisk, and then to press the button, which made the sentence appear on the screen. When the participants had finished reading the sentence, they pressed the button again, which, in most cases, started the next trial. In $25 \%$ of the trials the sentence was followed by a verification statement. The participants had to judge whether the statement was consistent with the content of the preceding sentence by pressing one of two buttons. This button press started the next trial.

The participants were instructed not to blink when reading the sentences. They were allowed to blink when they were reading a statement or fixating an asterisk.

\section{Results}

In an eye movement experiment, participants are free to move their eyes across the text as they want. This implies that not every word is fixated, which leads to missing data on some words in some trials. The amount of missing data varies depending on, among other things, the frequency and the length of a word (Rayner, 1998). Determiners, for example, are very often not fixated, among other things because they are short. Nouns, on the other hand, are on average much longer, and therefore they are almost always fixated. We therefore did not analyze the 
sentences word by word, but combined words into regions. The regions that were analysed are given in brackets in (18).

(18) Vanwege het onderzoek[ moeten][ de inbrekers,] die[ de bewoner][ beroofd] [ hebben][ in het][ weekend,][ nog een tijdje op het] politiebureau blijven.

Because of the investigation[must] [the burglars,] who[the occupant] [robbed] [have][over the][weekend,] [some time stay at the] police station.

The antecedent NPs (NP1) and the NPs in the relative clause (NP2) were analyzed as a whole. The relative pronoun was not analyzed, because it was almost always skipped. Instead, an additional analysis was done on the region consisting of the relative pronoun and NP2. The preposition and determiner of the clause-final prepositional phrase were analyzed separately from the noun, because we wanted to measure potential clause wrap-up effects at the noun. The last region we analyzed was the region following the relative clause, which finished the second line of text. This region contained at least two words.

If a participant skips a region frequently, the participants' mean in a condition may be based on only a few or even only one observation. This can cause outliers to have a strong effect on the results. Therefore, we decided only to include a subjects' mean in the statistical analyses if this mean was based on at least 4 out of the maximally possible 12 observations. In the item analysis the item mean was included if the mean was based on at least three out of the maximally possible eight observations. This procedure affected almost only the region that contained the auxiliary. At that position 14 of the 32 participants were excluded from the analysis by participants, and in the analysis by items, 22 of the 48 items were excluded. It appeared that some participants almost always skipped the auxiliary when they read the sentence. This does not imply, however, that they did not take up the disambiguating information provided by the auxiliary. Some readers typically only had one fixation in the verb cluster (past participle and auxiliary), and this fixation often was located at the end of the participle. These readers presumably have seen the number marking on the auxiliary parafoveally. Another region that was affected was the past participle: At that position there was one exclusion in the analysis by participants and one exclusion in the analysis by items. Also the region that contained the preposition and the determiner of the clause-final prepositional phrase was affected. There were two and three exclusions in the analysis by participants and items, respectively. Finally, at the noun of this prepositional phrase there were two exclusions in the analysis by items.

Two measures were computed. The first was the first-pass reading time, which is the time a reader spends in a region before leaving the region either to the left or to the right. We included the duration of the saccades between successive fixations in our measures, since we do not assume that lexical processing and sentence processing stops during saccades (cf. Cozÿn, 2000; Irwin, 1998). The first-pass reading time provides a good measure of the initial processing of a region. The second measure was the regression-path duration, defined as the time spent in a region in first pass before leaving that region to the right, plus all the time spent in regressing to earlier parts of the sentence (Konieczny, 1996; Konieczny et al., 1997).

For each of the regions defined above, two analyses of variance were computed, one with participants $(F 1)$ and one with items $(F 2)$ as a random variable. The factors included in the analyses were Animacy of Object (animate object vs inanimate object) and Clause Type (subject relative clause vs object relative clause). When there was an interaction between these factors, separate analyses of variance were computed for the Animate Object condition and the Inanimate Object condition, with the factor Clause Type (Subject Relative clause vs Object Relative clause). In the following the results for first-pass reading times and regression-path duration will be presented separately.

On average, the participants gave the correct answer to $92 \%$ of the comprehension questions.

First-pass reading times. Reading times shorter than $50 \mathrm{~ms}$ (5 cases, $0.05 \%$ ) were ex- 
cluded from further analysis. Reading times that were more than two standard deviations from the participant and item means at a given position in each condition (54 cases, 0.6\%), were excluded. The means by subjects of the first-pass reading times as a function of Clause Type and Animacy of Object are presented in Table 5.

At the verb in the main clause there were no main effects or interactions. At the antecedent NP (NP1) there was no main effect of Animacy of Object or Clause Type, but the interaction between these factors was significant: $F 1(1,31)=$ $6.67, p<.05, F 2(1,47)=4.22, p<.05$. In the separate analyses there was no effect of Clause Type in the sentences with an animate object: $F 1(1,31)=3.36, p=.08 ; F 2(1,47)=1.15$, $p=.29$. In the sentences with an inanimate object the antecedent NP was read significantly slower in the object relative clause condition than in the subject relative clause condition in the participant analysis $(F 1(1,31)=4.10, p=$ $.05)$, and there was a trend in the item analysis $(F 2(1,47)=3.60, p=.06)$.

There were no significant results at NP2, the NP in the relative clause. Also in the additional analysis on the region containing the relative pronoun and NP2 there were no significant results. At the past participle, there was one significant effect, the main effect of Animacy of Ob- ject: $F 1(1,30)=7.24, p<.05 ; F 2(1,46)=$ $3.94, p=.05$.

The sentences were disambiguated at the auxiliary. If readers use the disambiguating syntactic information immediately when it is available, one would expect an interaction of Animacy of Object and Clause Type in the first-pass reading times at this position. There was a main effect of Clause Type $(F l(1,17)=7.01, p<.05$; $F 2(1,25)=6.23, p<.05)$ and no main effect of Animacy of Object. The interaction between Animacy of Object and Clause Type was significant in the item analysis, whereas there was only a trend in the participant analysis: $F 1(1,17)=$ $4.23, p=.06 ; F 2(1,25)=9.30, p=.005$. The separate analyses showed that in the sentences with an animate object the object relative clauses led to a longer first-pass reading time than the subject relative clauses $(259 \mathrm{~ms}$ vs $230 \mathrm{~ms}$, $F 1(1,21)=6.29, p<.05 ; F 2(1,33)=10.09$, $p<.005)$. In the sentences with an inanimate object there was no effect of Clause Type (both $F$ 's $<1)$. Note that, as we indicated before, at this position there were many exclusions on the basis of insufficient data points. An analysis including also means based on fewer than four data points for participants and less than three data points for items yielded similar results.

At none of the regions after the auxiliary were there significant main effects or interactions.

\section{TABLE 5}

Mean First-Pass Reading Times in Experiment 2 as a Function of Animacy of Object and Clause Type

\begin{tabular}{|c|c|c|c|c|}
\hline & & & & \\
\hline & A & B & $\mathrm{C}$ & $\mathrm{D}$ \\
\hline & SR & OR & SR & OR \\
\hline Main clause & & & & \\
\hline Main clause verb & 257 & 266 & 257 & 260 \\
\hline NP1 (antecedent) & 374 & 353 & 366 & 392 \\
\hline Ambiguous Region & & & & \\
\hline NP2 & 358 & 369 & 371 & 361 \\
\hline Past participle & 316 & 317 & 304 & 292 \\
\hline Disambiguation & & & & \\
\hline Auxiliary & 230 & 259 & 239 & 243 \\
\hline Prepositional phrase & & & & \\
\hline Prep. + Det. & 256 & 260 & 246 & 252 \\
\hline Noun & 283 & 284 & 274 & 276 \\
\hline Main clause & & & & \\
\hline Rest of line & 516 & 514 & 504 & 493 \\
\hline
\end{tabular}


Regression path duration. Reading times shorter than $50 \mathrm{~ms}$ (4 cases, 0.04\%) and longer than $4000 \mathrm{~ms}$ (3 cases, $0.03 \%$ ) were excluded from further analysis. From the remaining reading times those that were more than two standard deviations away from the participant and item means at a given position in each condition (105 cases, 1.1\%), were excluded. The regression path durations and the percentages of regression for the other regions are presented in Table 6.

There were no significant main effects or interactions at the verb in the main clause. In the region containing NP1 there were no main effects of either factor. However, the interaction of Animacy of Object and Clause Type was significant: $F 1(1,31)=13.35, p=.001 ; F 2(1,47)=$ $14.02, p<.001$. In the conditions with an animate object there was a trend toward an effect of Clause Type in the participant analysis $(F 1(1$, $31)=3.38, p=.08)$, but not in the item analysis $(F 2(1,47)=1.93, p=.17)$. In the conditions with an inanimate object there was a significant effect of Clause Type: $F 1(1,31)=9.75, p<$ $.005 ; F 2(1,47)=14.10, p<.001$. At NP2 there were no significant main effects or interactions. Also, in the additional analysis on the region including the relative pronoun and NP2 there were no significant main effects or interactions.
At the past participle, there was a significant main effect of Animacy in the participant analysis only $(F 1(1,30)=5.05, p<.05$; $F 2(1,46)=2.56, p=.12)$, a significant main effect of Clause Type in the participant analysis only $(F 1(1,30)=4.38, p<.05 ; F 2(1$, $46)=1.65, p=.20)$, and no interaction. At the auxiliary there was a main effect of Animacy in the item analysis only: $F 1(1,17)=$ $2.56, p=.12 ; F 2(1,25)=2.56, p<.05$. Although the pattern of results was similar to the pattern of results in the first-pass reading times, the main effect of Clause Type was only marginally significant in the participant analy$\operatorname{sis}(F 1(1,17)=4.11, p=.06 ; F 2<1)$ and the interaction was only marginally significant in the item analysis $(F 1<1 ; F 2(1,25)=3.76$, $p=.06)$. The lack of significant effects in the regression path duration at this position may be due to the small percentage of regressions at this position. The inclusion of the regression path data may only have increased the variance in the data, which may have led to the disappearance of the significant effect that was present in the first-pass reading times. At the region immediately following the auxiliary (the preposition and the determiner of the prepositional phrase) there were no significant main effects or interactions.

\section{TABLE 6}

Regression Path Duration in Experiment 2 as a Function of Animacy of Object and Clause Type (Percentages of Regression are Given in Parentheses)

\begin{tabular}{|c|c|c|c|c|}
\hline & \multicolumn{2}{|c|}{ Animate object } & \multicolumn{2}{|c|}{ Inanimate object } \\
\hline & A & B & $\mathrm{C}$ & $\mathrm{D}$ \\
\hline & SR & OR & SR & OR \\
\hline \multicolumn{5}{|l|}{ Main clause } \\
\hline Verb & $300(12)$ & $310(12)$ & $320(12)$ & $309(11)$ \\
\hline NP1 & $519(31)$ & $481(27)$ & $491(26)$ & $559(29)$ \\
\hline \multicolumn{5}{|c|}{ Ambiguous region } \\
\hline NP2 & $422(15)$ & 437 (13) & $432(14)$ & $434(16)$ \\
\hline Past participle & $339 \quad(5)$ & $331 \quad(5)$ & 333 (6) & $305 \quad(4)$ \\
\hline \multicolumn{5}{|l|}{ Disambiguation } \\
\hline Auxiliary & $266 \quad(6)$ & $291 \quad(5)$ & 255 (3) & $264(4)$ \\
\hline \multicolumn{5}{|c|}{ Prepositional phrase } \\
\hline Prep. + Det. & 331 (14) & $319(12)$ & $324(14)$ & $299(11)$ \\
\hline Noun & $342(12)$ & $379(16)$ & $350(14)$ & $319(11)$ \\
\hline \multicolumn{5}{|l|}{ Main clause } \\
\hline Rest of line & $604(18)$ & $630(18)$ & $590(15)$ & $579(17)$ \\
\hline
\end{tabular}


If the need for a reanalysis during the reading of a clause affects the wrap-up processes at the end of the clause one would expect an interaction of Animacy of Object and Clause Type at the noun in the prepositional phrase, which was the last word of the relative clause. At this position, there was a significant effect of Animacy of Object in the participant analysis $(F 1(1,31)=$ 5.01, $p<.05)$, but not in the item analysis $(F 2(1,45)=1.98, p=.17)$. There was no main effect of Clause Type at this position. There was a significant interaction of Clause Type and Animacy of Object: $F 1(1,31)=7.01, p<.05$; $F 2(1,45)=4.58, p<.05$. Again, reading times were longer in the object relative clauses in the conditions with an animate object: $F 1(1,31)=$ $3.19, p=.08 ; F 2(1,45)=4.50, p<.05$. In the conditions with an inanimate object there was a trend toward an effect in the opposite direction in the participant analysis $(F l(1,31)=3.56$, $p=.07)$, but not in the item analysis $(F 2(1$, $47)=1.58, p=.22$ ).

At the region after the relative clause there was a trend toward an effect of Animacy of Object in the item analysis, but not in the participant analysis: $F 1(1,31)=1.30, p=.26$; $F 2(1,47)=3.63, p=.06$. There were no other significant main effects or interactions.

\section{Discussion}

The eye-movement experiment shows a difference in processing difficulty between the subject and object relative clauses when both protagonists are animate. This difference completely disappears when the object of the relative clause is inanimate. When the object is inanimate, there is no trace of a difference in processing difficulty between subject and object relative clauses. In this respect, the selfpaced reading experiment and the eye-movement experiment give the same result.

In Experiment 1, an interaction between Animacy of Object and Clause Type was found at the word after the auxiliary. The question was whether this interaction was a spillover effect from the auxiliary, or whether it was present only in the clause wrap-up. The data from the eye-movement experiments show that the effect is not delayed, because the interaction was found at the auxiliary itself, in the first-pass reading times. Since the auxiliary was not clause-final in this experiment, the effect cannot be due to clause wrap-up.

Apart from the interaction of Animacy of Object and Clause Type in the first-pass reading times at the auxiliary, there was also an interaction of these factors in the regression path duration at the clause-final noun. Reading times in object relative clauses were only delayed when the object of the relative clause was animate. The interaction at this position can be interpreted as a clause wrap-up effect. Thus, both an immediate and a wrap-up effect show up in the data.

At the past participle, a main effect of Animacy was found. Again, one must be careful in interpreting this main effect, since different past participles were used in the animate object and the inanimate object condition, and the two sets of past participles differed at least with respect to frequency. However, the fact that the main effect of animacy showed up at the past participle in this experiment suggests that the main effect of animacy found at the auxiliary in Experiment 1 was indeed spillover from the past participle.

The results at the antecedent NP indicate that the animacy manipulation was effective. Both in the first-pass reading time and in the regression path duration in the inanimate object condition there was a difference in reading time between the animate antecedent NP of the subject relative clause and the inanimate antecedent NP of the object relative clause. The problem in interpreting this effect is that the comparison is made between different sets of nouns. Though the nouns were matched for mean length and for frequency, there may have been other differences between the sets of words that caused these differences in reading times. However, the effect is perfectly in line with the findings of Weckerly and Kutas (1999), who found that ERPs to an inanimate noun in subject position, that was the antecedent of a relative clause, were more negative than the ERPs to an animate noun in the same position.

\section{GENERAL DISCUSSION}

Until now, experiments in Dutch and German have consistently shown that object relative 
clauses are more difficult to process than subject relative clauses (Brown et al., 2000; Schriefers et al., 1995; Mecklinger et al., 1995; Vonk et al., 2000). The experiments also showed that the manipulation of thematic fit did not result in the elimination of the processing difficulty in object relative clauses with two animate protagonists compared with subject relative clauses. The studies used semantically biased verbs of the type used in the animate object condition of the present study. The results show that this semantic information was not enough to override the preference for subject relative clauses. The results of the animate object conditions of the present study, which also used semantically biased verbs, provide a replication of this result. On the basis of these results one could argue that the manipulation of thematic fit does not affect the processing of subject and object relative clauses. However, the semantic manipulation of animacy clearly did affect processing. In the conditions with an inanimate object, there were no reading time differences between subject and object relative clauses. Thus, animacy influences the parse of relative clauses.

The theories of relative clause processing discussed in the introduction do not predict the effect of animacy. Both the AFS and the SPLT claim that readers analyze the clause as a subject relative clause immediately at the relative pronoun. The AFS claims that the parsing decision is due to the difference in syntactic structure between subject and object relative clauses, and this difference is the same irrespective of whether the object of the relative clause is animate or inanimate. The SPLT posits that the choice for a subject relative clause is based on the number of categories that must be predicted. This number of categories is also independent of animacy. Hence, according to both theories, the animacy of the object of the relative clause does not influence the parsing decision made at the relative pronoun.

Thus, both accounts predict that a reanalysis is necessary in object relative clauses irrespective of the animacy of the object. The present data are clearly inconsistent with this prediction. However, one may argue that readers did revise a potential commitment for a subject relative clause analysis while reading the ambiguous region. Such an effect may not show up in the data, since readers can make this reanalysis at any point in the ambiguous region, which is four words long (i.e., from the relative pronoun up to and including the past participle). Hence, the data do not exclude entirely the possibility of a reanalysis in the object relative clauses with an inanimate object.

However, the present data do show that animacy affects the processing of relative clauses. On the basis of this result, one must seriously explore the possibility that the semantic cue of animacy immediately guides the choice for an analysis of the relative clause. This direct guidance may take several forms. First, if readers choose an analysis of the relative clause immediately when they read the relative pronoun, the animacy of the antecedent may determine the preferred analysis of the relative clause. When the antecedent is animate, readers may choose the subject relative clause reading, but when the antecedent is inanimate they may choose the object relative clause reading. If that is the case, no processing difficulty is expected in object relative clauses with an inanimate object, since the antecedent is inanimate in these cases. Second, one could assume that readers do not choose between a subject and object relative clause reading when they read the relative pronoun (which is the case in the AFS and the SPLT), but only when they process the NP that follows it. Then, at that position, readers are faced with two entities that compete for the role of subject and object of the relative clause. One of the sources of information that readers can use to resolve this competition is the animacy of the NP's involved. If the NP's differ in animacy, the reader chooses the animate NP as the subject of the relative clause. This account predicts that there will be no difference between subject relative clauses and object relative clauses in the cases in which the subject is animate and the object is inanimate.

However, what happens when the NP's are equal in animacy? In that case, readers may use the default assumption that the first NP is the subject. There are several reasons why this is a plausible strategy. First, this may be a result of 
the givenness of the antecedent in the relative clause (Zubin, 1979). Second, readers do not have to change the topic. The antecedent has already been introduced, and is therefore available to the reader as topic. This topic is preserved when the antecedent is the subject of the relative clause (cf. MacWhinney \& Pléh, 1988; MacWhinney, 1977).

As a matter of fact, the strategy to postpone the initial analysis until the first constituent after the relative pronoun may be useful in Dutch. In object relative clauses, the subject has to occur immediately after the relative pronoun. Thus, if the first constituent after the relative pronoun is not an NP, as in (19), the reader knows that the sentence must be a subject relative clause. The relative clause in (20) is ungrammatical, because the subject (vrouwen) is not directly adjacent to the relative pronoun, as in (21), the grammatical version of (20):

(19) Dit is de man die gisteren de vrouwen gezien heeft.

This is the man who yesterday the women seen has.

(20) *Dit is de man die gisteren de vrouwen gezien hebben.

This is the man who yesterday the women seen have.

(21) Dit is de man die de vrouwen gisteren gezien hebben.

This is the man who the women yesterday seen have.

Only if the constituent after the relative pronoun is an NP, as is the case in all of our sentences, there is ambiguity between a subject relative clause and an object relative clause. In that case readers can use semantic or pragmatic information to guide their analysis of the relative clause.

The previous explanations imply that it is the animacy of the entities per se that guides the assignment of the syntactic functions. However, one may also argue that readers do not commit themselves to an analysis of the relative clause before they read the past participle. On reading the past participle, the thematic fit of the entities with the argument roles assigned by the verb guides the assignment of syntactic functions (cf. Trueswell et al., 1994). This leads to a choice for the animate entity as the subject. The absence of an effect of thematic fit in the experiments with two animate NPs (Brown et al., 2000; Mecklinger et al., 1995; Schriefers et al., 1995; Vonk et al., 2000) may then be a result of the fact that the manipulation of thematic fit was not strong enough to override the preference for the relative pronoun to be the subject of the relative clause.

Whatever the precise location of the effect of animacy, the results of our experiments show that the semantic factor of animacy affects the analysis of relative clauses. The data show that the possibility that readers use semantic information to guide the parse of the relative clause is a serious alternative to theories that claim that the initial parsing decision is driven by syntactic strategies.

\section{REFERENCES}

Brown, C. M., Hagoort, P., \& Vonk, W. (2000). Processing relative clauses in Dutch: An analysis with event-related potentials. In preparation.

CELEX Dutch database (Release N32) [On-line]. (1998). Available: Nijmegen: Centre for Lexical Information [Producer and Distributor]

Cozijn, R. (2000). Integration and inference in understanding causal sentences. Unpublished doctoral dissertation, University of Tilburg, The Netherlands.

Ford, M. (1983). A method for obtaining measures of local parsing complexity throughout sentences. Journal of Verbal Learning and Verbal Behavior, 22, 203-218.

Fox, B. A., \& Thompson, S. A. (1990). A discourse explanation of the grammar of relative clauses in English conversation. Language, 66, 297-316.

Frauenfelder, U., Segui, J., \& Mehler, J. (1980). Monitoring around the relative clause. Journal of Verbal Learning and Verbal Behavior, 19, 328-337.

Frazier, L. (1987). Syntactic processing: Evidence from Dutch. Natural Language and Linguistic Theory, 5, 519-559.

Frazier, L., \& Flores d'Arcais, G. B. (1989). Filler driven parsing: A study of gap filling in Dutch. Journal of Memory and Language, 28, 331-344.

Gibson, E. (1998). Linguistic complexity: Locality of syntactic dependencies. Cognition, 68, 1-76.

Haegeman, L. (1994). Introduction to government and binding theory. Cambridge, MA: Blackwell.

Henderson, J. M., \& Ferreira, F. (1990). Effects of foveal processing difficulty on the perceptual span in reading: Implications for attention and eye movement control. Journal of Experimental Psychology: Learning, Memory, and Cognition, 16, 417-429.

Holmes, V. M., \& O'Regan, J. K. (1981). Eye fixation patterns during the reading of relative-clause sentences. 
Journal of Verbal Learning and Verbal Behavior, 20, 417-430.

Irwin, D. E. (1998). Lexical processing during saccadic eye movements. Cognitive Psychology, 36, 1-27.

Just, M. A., Carpenter, P. A., \& Woolley, J. D. (1982). Paradigms and processes in reading comprehension. Journal of Experimental Psychology: General, 111, 228238.

King, J., \& Just, M. A. (1991). Individual differences in syntactic processing: The role of working memory. Journal of Memory and Language, 30, 580-602.

King, J. W., \& Kutas, M. (1995). Who did what and when? Using word- and clause-level ERPs to monitor working memory usage in reading. Journal of Cognitive Neuroscience, 7, 376-395.

Konieczny, L. (1996). Human sentence processing: A semantics-oriented parsing approach. IIG-Berichte $3 / 96$.

Konieczny, L., Hemforth, B., Scheepers, C., \& Strube, G. (1997). The role of lexical heads in parsing: Evidence from German. Language and Cognitive Processes, 12, 307-348.

MacWhinney, B. (1977). Starting points. Language, 53, $152-168$.

MacWhinney, B, \& Pléh, C. (1988). The processing of restrictive relative clauses in Hungarian. Cognition, 29, 95-141.

Mecklinger, A., Schriefers, H., Steinhauer, K., \& Friederici, A. D. (1995). Processing relative clauses varying on syntactic and semantic dimensions: An analysis with event-related potentials. Memory \& Cognition, 23, 477-494.
Radford, A. (1997). Syntactic theory and the structure of English: A minimalist approach. Cambridge: Cambridge University Press.

Rayner, K. (1998). Eye movements in reading and information processing: 20 Years of research. Psychological Bulletin, 124, 372-422.

Rayner, K., Kambe, G., \& Duffy, S. A. (2000). The effect of clause wrap-up on eye movements during reading. The Quarterly Journal of Experimental Psychology, 53A, 1061-1080.

Schriefers, H., Friederici, A. D., \& Kühn, K. (1995). The processing of locally ambiguous relative clauses in German. Journal of Memory and Language, 34, 499520.

Trueswell, J. C., Tanenhaus, M. K., \& Garnsey, S. M. (1994). Semantic influences on parsing: Use of thematic role information in syntactic ambiguity resolution. Journal of Memory and Language, 33, 285-318

Vonk, W., Brown, C. M., \& Hagoort, P. (2000). Processing relative clauses in Dutch: An analysis with self-paced moving window and eye-movement reading times. In preparation.

Weckerly, J., \& Kutas, M. (1999). An electrophysiological analysis of animacy effects in the processing of object relative sentences. Psychophysiology, 36, 559-570.

Zubin, D. A. (1979). Discourse function of morphology: The focus system in German. In T. Givón (Ed.), Syntax and semantics: Discourse and syntax (vol. 12). New York: Academic Press.

(Received December 13, 1999)

(Revision received July 5, 2001) 